\title{
Universidad y Paz
}

MERNANDO GUTIÉRREZ HOVOS*

Antes de iniciar con la temática escogida para disertar en este foro, deseo resaltar la presencia en el auditorio de los jóvenes estudiantes tanto de la universidad como de la escuela secundaria. A ellos, especialmente, va dirigido el mensaje que he preparado para esta audiencia ya que si vamos a hablar de construir y edificar procesos de Paz es con la juventud, básica y fundamentalmente, con quien debemos dialogar.

Lo anterior no quiere decir que los adultos deban retirarse del auditorio. Todo lo contrario; deben quedarse para que interactuemos dialógicamente con la juventud alrededor de este tema tan complejo, y últimamente tan manipulado, que es la Paz.

Empezaré haciendo referencia, precisamente, a algunos escenarios en los cuales últimamente la Paz aparece como el actor principal y que me hacen hablar de manipulación del término Hablamos, por ejemplo, de diálogos de Paz; negociaciones de Paz; marchas por la Paz; Décimo Encuentro Nacional de Escritores "Una cita con la Paz". Pero, ¿qué cosa es la Paz?. Acaso una resbaladiza categoría filosófica o moral tan etérea como libertad, democracia, igualdad? O, uno de esos términos primitivos o indefinidos que emplean los matemáticos en la construccion de los llamados sistemas formales?. Es la Paz el ambiente que rodea y que regula el discurrir de la vida en las sociedades paradisíacas que nos ofrecen las religiones y los partidos políticos?. Será la Paz ese conjunto de pañuelos blancos que se agitan alados en el aire para despedir a quien ha dejado de ser en razón de la violencia?. O, a lo mejor, una bandada de palomas blancas que se sueltan desde la plaza principal de cualquier pueblo para calmar el corazón de los violentos?. O, preferiblemente, nos quedamos con la definición oficializada por el diccionario según la cual, la Paz es una virtud que pone en el ánimo tranquilidad y sosiego, opuestos a la turbación y a las pasiones. Genio pacífico, sosegado y apacible. Siendo apacible igual a manso, dulce y agradable en la condición y en el trato. Con lo cual, la Paz se nos confunde con expresiones como domesticación, sometimiento y servilismo.

Texto de la ponencia presentada por el profesor Gutiérrez en el foro sobre "La Usco y la Paz" realizado durante el Encuentro Nacional de Escritores que tuvo lugar en Neiva los días 6-7-8 de abril del 2001.

" Profesor de la Facultad de Educación, programa de Matemáticas y Física. 
Todos estos elementos nos aproximan a la existencia de un imaginario colectivo en relación con la interpretación del término que hace de él un referente para una convivencia más equilibrada y armoniosa; un prerrequisito fundamental para la misma existencia de las sociedades; un sueño; una utopía que busca su lugar para realizarse; una sana y bien intencionada aspiración colectiva; un estado ideal de convivencia humana soportado en relaciones de solidaridad, respeto por las diferencia y el reconocimiento del otro.

He dicho bien, se trata de un imaginario porque nunca hemos alcanzado (por lo menos después de la llegada de los Españoles) un ambiente de convivencia como los tipificados anteriormente. Mi generación, muchísimas generaciones anteriores a la mía, y la generación de ustedes, los jóvenes presentes, no sabemos qué es vivir en Paz. Siempre se nos ha negado esta oportunidad; tal vez, porque hay a quienes la ausencia de tales estados de Paz les representa un rentable negocio. Por difícil que sea de creer, existen personas que no están interesadas en la Paz; es más, no les conviene la Paz porque han hecho de todo aquello contrario a ella el gran negocio de su vida. Por ejemplo, alrededor de la guerra permanente y sistemática entre países o al interior de los mismos, que con base en las anteriores reflexiones sobre la Paz le resulta antagónica, se ha desarrollado una de las industrias económicamente más poderosas del mundo: La industria de las armas, cuyo campo de acción no se limita únicamente a producir los artefactos para la guerra sino a fomentar la guerra misma con el fin de garantizarle mercado a sus mortíferos productos. Al lado de esta industria están los grandes grupos financieros que comprometen la independencia y la autonomía de los estados con sus onerosos créditos para que éstos puedan armarse "hasta los dientes" y enfrentar sus guerras.

Igualmente, no les conviene la Paz a los grandes acaparadores de la riqueza y de la tierra pues, necesariamente, la Paz deberá ser contraria a todo lo que corresponda a monopolización y concentración; la Paz debe estar más próxima a los procesos que impliquen lo colectivo y la distribución equitativa de la propiedad y la riqueza.

Si bien es cierto que no existe un pleno acuerdo sobre lo que es la Paz ni sobre las formas de construirla, si parece existir (al menos tácitamente) sobre lo que no es y sobre como no se construye. En consecuencia, deben descartarse las interpretaciones acomodaticias que nos pretenden imponer quienes agencian la sumisión, el conformismo y la búsqueda de la armonía espiritual hacia el interior del individuo como los únicos estados de Paz que pueden ser alcanzados por el nombre. La Paz no puede ser algo que se exalta ofreciendo la mejilla izquierda cuando nos abofetean la derecha. La Paz no puede estar asociada con el comportamiento ladino y adulador que nos permite 
acceder a las migajas que caen de la mesa del patrón. No se construyen procesos de Paz invitando a sufrir en silencio y con resignación la carencia de los recursos mínimos necesarios para diferenciar la existencia humana de la existencia animal.

La Paz implica el colectivo social y debe ser contraria al enconchamiento, el enclaustramiento, la insolidaridad, el dejar a los demás con sus problemas y dedicarnos individualmente a convivir (ni siquiera a enfrentar) con los nuestros. Cuando se nos impide (por cualquier medio) disentir o diverger, se nos niega la oportunidad de ser diferentes para poder identificar lo que nos iguala, y a lo máximo que se nos deja aspirar es a uniformarnos por lo bajo para ingresar al ejército de las reservas que hacen la cola a lo largo de la cual, supuestamente, se asciende en el escalafón social. No se fomenta la paz cuando se pide renunciar a la construcción de utopías terrenas para sublimar los paraísos celestiales.

Es lógico, y debe quedarnos suficientemente claro, que no todo puede ser color de rosa en torno a la Paz. No necesariamente tiene que corresponder a la igualdad absoluta entre los seres humanos, la vida muelle, la satisfacción automática de nuestros deseos y caprichos, los valles fértiles recorridos por ríos de leche y miel. Un estado de quietud semejante negaría la vida misma pues ésta se genera y desarrolla en el movimiento, la confrontación y la superación de las contradicciones.

No parece ser tarea fácil alcanzar ese estado de convivencia que se aproxime a lo que concebimos como una sociedad en Paz. Debe ser muy difícil; sobre todo si tenemos en cuenta que el ser humano está luchando por cons- truir ese ambiente favorable para el desarrollo de su existencia plena desde la aparición de los primeros grupos étnicos sin que aún haya podido estabilizar en el tiempo los logros conseguidos en tal sentido.

Sin embargo, y por difícil que resulte esta empresa, no podemos renunciar a ella. El propósito deberá ser alcanzar un estado de organización social que permita el desarrollo pleno de la potencialidad creativa del hombre puesta, en primera instancia, al servicio de su bienestar material y espiritual. En torno a este ideal tendrá que movilizarse la humanidad para hacer de la Paz una construcción colectiva que nos convoque y comprometa a todos motivándonos a dejar de lado los intereses particulares (sin llegar a la privación o al sufrimiento). Un ordenamiento social donde prime el interés colectivo y lo público sea la fundamentación de la conciencia social sin que ello implique la negación de la subjetividad o la enajenación del individuo en la uniformidad de la masificación.

Si bien es cierto que este propósito nos compromete a todos y debe ser promovido en todas las instancias organizativas de nuestra sociedad, partiendo del núcleo familiar y el más inmediato entorno social lla cuadra, el barrio, la comuna, la ciudad, etc.), también lo es que corresponde fundamentalmente a las instituciones de educación formal asumir la tarea de formar ciudadanos en Paz y para la Paz. Igualmente le compete a estas entidades proponer y experimentar modelos de convivencia pacífica orientados a construir sociedad civil y a cultivar los valores de la solidaridad, el respeto por la opinión ajena (sobre todo cuando ésta difiere de la nuestra), el reconocimiento de las diferencias y la búsque- 


\section{6}

Universidad Surcolombiana

da de soluciones consensuadas a los diferentes probiemas que afectan la vida en comunidad.

En el caso particular de nuestro país, desafortunadamente, el sistema educativo no contribuye a generar procesos que fomenten en los estudiantes actitudes asociadas con los prerrequisitos para la Paz. Muy por el contrario, reproduce, alimenta y estimula todas aquellas que niegan la Paz: El autoritarismo, la antidemocracia, el individualismo, la insolidaridad, la competencia tramposa y desleal que desconoce el afecto, la familiaridad y la amistad.

Las Universidades, por ejemplo, estando ubicadas en la cúspide del sistema educativo, no lideran institucionalmente procesos integrales que motiven y estimulen la construcción de una cultura ciudadana orientada hacia la convivencia pacífica, solidaria y dignificante de la condición humana. Su preocupación fundamental continua siendo la profesionalización en las diferentes áreas del conocimiento para ofertar y competir en el mercado del trabajo. Cuando tímidamente las reformas curriculares incorporan en las asignaturas de los planes de estudio actividades tendientes a sensibilizar y comprometer los estudiantes en una práctica social basada en los principios de la solidaridad y el respeto por la diferencia, como condiciones indispensables para la reafirmación de la identidad cultural y la determinación de los límites de la tolerancia, las prácticas despóticas de maestros y directivos desvirtúan estos propósitos y convierten tales asignaturas en un simple ejercicio intelectual fácilmente superable en la medida que se le haga "creer" al maestro que se está de acuerdo con él. Continúa, pues, haciendo falta el compromiso institucional para alcanzar la tan mentada y anhelada formación integral del profesional universitario que no ha de ser otra que la de un hombre sólidamente fundamentado en una disciplina científica, motivado por una profunda sensibilidad social y dispuesto para la solidaridad.

Pero no solo la práctica de Maestros y Directivos desvirtúa los esfuerzos de la Universidad por construir procesos que comprometan e integren su entorno en experiencias de convivencia comunitaria, pacífica y solidaria. La Universidad misma es violentada permanente $y$ sistemáticamente desde afuera y desde adentro para negarle la posibilidad de desarrollar sus propuestas sobre construcción de procesos de Paz, de ciudadanía y de civilidad.

Desde afuera la violentan los sucesivos gobiernos tanto liberales como conservadores que en lo fundamental mantienen el establecimiento con el cual protegen los intereses económicos de los organismos financieros internacionales, que han hecho del país un gran supermercado, y de las poquísimas familias colombianas (no más de 10\% de la población) que se han apropiado de $80 \%$ de nuestras riquezas; su- 
cesivos gobiernos que desconocen la autonomía universitaria imponiéndole a las Universidades Públicas sus organismos de dirección y la conformación de los mismos; negándoles los recursos económicos que requieren para desarrollar sus planes y programas académico-científicos. Gobiernos que continuamente están chantajeando a la Universidad para que renuncie a su, ya de por sí, debilitada autonomía, a cambio del plato de lentejas representado en la limosna de unos pesos lque obligatoriamente debieron darle) con los cuales mitigar sus permanentes angustias económicas. y les facilite su injerencia privatizadora a favor de los mandatos de la banca multinacional. Violentan la Universidad lespecialmente la de provincial los politiqueros de todos los matices quienes inescrupulosamente pretenden hacer de ella su fortín burocrático pidiendo cupos para estudiantes de bajo rendimiento académico y empleados innecesarios con los cuales ayudan "generosamente" a incrementar la onerosa nómina paralela que agobia las Universidades: todo ello argumentando gestiones oficiales en la búsqueda de recursos económicos o en la tramitación de proyectos en lo cual son cada vez menos eficaces sin menoscabar su discreto encanto para manipular Rectores y Administrativos.

Actualmente, a partir del famoso proceso de elección "Democrática" de Rectores, aparece un nuevo grupo de violentadores externos de la Universidad. Unos especímenes insaciables devoradores de los presupuestos oficiales; se trata de los contratistas, cuya carta de presentación es el 20 o el 25 por ciento de oferta sobre el valor de cada contrato y su extraordinaria capacidad para sobornar. Ellos pueden colocar, en última instancia, los Rectores financiándoles sus campañas politiqueras (no académicas) y tienen muchísimo que ver en los actuales hechos de sangre que se están presentando en los claustros universitarios.

Violentan la Universidad las diferentes organizaciones armadas /de derecha o de izquierda) que pretenden hacer del campus universitario escenario de confrontación bélica; los primeros para acallar lo poco de pensamiento crítico que pueda haber en ella, intimidar la reflexión y aislar la Universidad del análisis y el debate de los problemas sociales, políticos y económicos que afectan el país: los segundos buscando audiencia y legitimidad entre la juventud universitaria.

Desde adentro la violentan los Rectores que en aras de la autonomía asumen un poder omnímodo y autocrático para administrar en favor de los políticos que los apadrinan, los amigos que les robustecen el ego y los contratistas que los retribuyen con el $25 \%$.

La violentan las normas reglamentarias que establecen regímenes disciplinarios de corte militarista con los cuales no se orienta ni estimula la convivencia sino que se castiga y se 
intimida cualquier intento innovador que ponga en peligro la perpetuación de quienes usufructúan el poder.

La violentan los profesores que asumen posiciones doctrinarias en sus cátedras y no aceptan el debate que enriquece ni el cuestionamiento que aclara o corrige; los profesores que hacen abstracción de la condición humana de sus estudiantes para tratarlos como receptáculos depositarios de información (en muchísimos casos muy poco útil, casi siempre de baja calidad). Profesores que no ven en la Universidad más que un medio de ganarse la vida, un trabajo como cualquier otro que les permite obtener un salario y les posibilita la oportunidad de vivir relativamente bien.

La Universidad, desde adentro, es violentada por los estudiantes que pasan por ella "sin romperla ni mancharla" y permanecen ciegos, sordos e indiferentes a los llamados que invitan a un compromiso social que trascienda los estrechos limites de los programas curriculares correspondientes a cada carrera. Estudiantes cuyo objetivo es titularse "a cualquier precio" para adquirir una patente que les permita ofertarse, como mano de obra calificada, en el mercado del capital.

¿Qué hacer entonces para que además de comprometer realmente a la Universidad en la implementación de procesos que contribuyan a construir relaciones de convivencia cordial que allanen los caminos hacia una sociedad en Paz, sin que se nos quede en el simple ejercicio teórico, garanticemos la supervivencia de la Universidad misma como foro permanente del pensamiento humanístico?

No se trata solamente de reorientar el discurrir de la Universidad para que asuma el liderazgo en la conducción de la sociedad hacia formas superiores de vida donde haya reciprocidad entre unas condiciones de existencia dignas para todos sus miembros y una convivencia pacífica y solidaria. Es necesario, ahora más que nunca, garantizar la supervivencia de la Universidad como una de las instituciones públicas fundamentales de la sociedad, restituyéndole teórica y prácticamente su condición de Alma Máter en el sentido de fuente de vida intelectual, faro de luz guía, manantial de sabiduría para la búsqueda de solución a los problemas tanto materiales como espirituales de la sociedad. Debemos hacer de la Universidad una institución más académica que politécnica, abierta para las manifestaciones culturales, políticas, filosóficas, ideológicas, artísticas, científico-técnicas etc., que germinen como producto de un trabajo sistemático y serio en cualesquiera sectores de la sociedad.

Queremos y necesitamos una Universidad arraigada en su entorno; una Universidad que se haga necesaria para el desarrollo integral de la sociedad y que más que profesionalizar y entregar títulos que habiliten para el ejercicio de una profesión, prepare al individuo para el goce y el disfrute pleno de la vida en la medida que pueda diferenciarse, reconocerse, aceptarse y valorarse a si mismo y sepa integrarse solidariamente, sin renunciar a su libre albedrío, al colectivo social al cual pertenece. 